\title{
A CONTROVERSA EVOLUÇÃO DA INDÚSTRIA BRASILEIRA DE MÁQUINAS AGRÍCOLAS DE 1920 A 2020
}

\author{
Henrique Rudolfo Hettwer ${ }^{1}$
}

Recebido em: 01/10/2020

Aprovado em: 10/11/2020

\begin{abstract}
Resumo: Este artigo objetiva a análise histórica do segmento de máquinas agrícolas (tratores e colheitadeiras) no Brasil, refletindo os entraves geopolíticos para a indústria genuinamente nacional e sua evolução. Trata-se de pesquisa apoiada em referencial teórico objetivando a compreensão dos contextos históricos, a concepção de desenvolvimento nacional e a gênese e desenvolvimento do segmento industrial. Como ilustração e verificação das contradições dos contextos históricos houve a análise de dados oficiais e corporativos, contraditados com as potencialidades brasileiras, as experiências e os impedimentos para a plena realização nacional do segmento, discutidas sob as premissas de autores da história econômica do Brasil. Concluise que os entraves históricos para a industrialização brasileira foram influenciados por oligarquias nacionais em aliança com o capital estrangeiro. Com a Revolução de 1930 mudaram-se os paradigmas, foi erguida a indústria de base e instauradas políticas nacionaisdesenvolvimentistas que potencializaram o crescimento econômico, suscitando a gênese da indústria brasileira de máquinas agrícolas. Porém, anos mais tarde, foram revistos pressupostos, abrindo-se o mercado para a instalação de empresas estrangeiras no país. A indústria nacional não resistiu à força estrangeira e à desproteção estatal a partir da segunda metade da década de 1970, desconstituindo-se, desnacionalizando-se, formando o atual oligopólio estrangeiro.
\end{abstract}

Palavras-chave: Máquinas Agrícolas; Desenvolvimento; Desnacionalização; Neoliberalismo.

\section{LA POLÉMICA EVOLUCIÓN DE LA INDUSTRIA BRASILEÑA MAQUINARIA AGRÍCOLA DE 1920 A 2020}

Resumen: Este artículo tiene como objetivo el análisis histórico del segmento de maquinaria agrícola (tractores y cosechadoras) en Brasil, reflejando las barreras geopolíticas para la industria genuinamente nacional y su evolución. Se trata de una investigación sustentada en un marco teórico orientado a comprender los contextos históricos, el concepto de desarrollo nacional y la génesis y desarrollo del segmento industrial. Como ilustración y verificación de las contradicciones de los contextos históricos, se realizó el análisis de datos oficiales y corporativos, contradiciendo el potencial brasileño, las experiencias y los impedimentos para la plena realización nacional del segmento, discutidos bajo las premisas de autores de la historia económica de Brasil. Se concluye que las barreras históricas a la industrialización brasileña fueron influenciadas por oligarquías nacionales en alianza con el capital extranjero. Con la Revolución de 1930, se cambiaron los paradigmas, se erigió la industria básica y se introdujeron políticas nacional-desarrollistas que potenciaron el crecimiento económico, levantando la génesis de la industria brasileña de maquinaria agrícola. Sin embargo, años después, se

\footnotetext{
${ }^{1}$ Doutorando em Geografia PPGEO-UFSM. E-mail: henriquehettwer@gmail.com. Orcid: https://orcid.org/0000$\underline{0003-0353-4588 .}$.
} 
revisaron los supuestos, abriendo el mercado para la instalación de empresas extranjeras en el país. La industria nacional no resistió la fuerza extranjera y la desprotección estatal a partir de la segunda mitad de la década de 1970, deconstruyéndose, desnacionalizándola, formando el actual oligopolio exterior.

Palabras clave: Maquinaria Agrícola; Desarrollo; Desnacionalización; Neoliberalismo.

\title{
THE CONTROVERSY EVOLUTION OF THE BRAZILIAN INDUSTRY OF AGRICULTURAL MACHINES FROM 1920 TO 2020
}

\begin{abstract}
This article aims at the historical analysis of the agricultural machinery segment (tractors and harvesters) in Brazil, reflecting the geopolitical barriers for the genuinely national industry and its evolution. This is a research supported by a theoretical framework aimed at understanding the historical contexts, the concept of national development and the genesis and development of the industrial segment. As an illustration and verification of the contradictions of the historical contexts, there was the analysis of official and corporate data, contradicted with the Brazilian potential, the experiences and the impediments to the full national realization of the segment, discussed under the premises of authors of history economic growth in Brazil. It is concluded that the historical barriers to Brazilian industrialization were influenced by national oligarchies in alliance with foreign capital. With the 1930 Revolution, paradigms were changed, the basic industry was erected and national-developmentalist policies were introduced which potentiated economic growth, raising the genesis of the Brazilian agricultural machinery industry. However, years later, assumptions were revised, opening the market for the installation of foreign companies in the country. The national industry did not resist foreign force and state deprotection from the second half of the 1970s onwards, deconstructing itself, denationalizing it, forming the current foreign oligopoly.
\end{abstract}

Keywords: Agricultural Machinery; Development; Denationalization; Neoliberalism.

\section{Introdução}

Este artigo traz uma análise acerca da evolução da indústria brasileira de máquinas agrícolas, especificamente de tratores e colheitadeiras, no período de 1920 a 2020, trazendo a originalidade da discussão sobre a tecnologia no campo e sua dialética na história agrária do país. Por sua geografia privilegiada, o Brasil apresenta um dos mais potentes territórios agrícolas do planeta, estando entre os líderes mundiais de diversas culturas como soja, café, milho, cacau, arroz, feijão, algodão, dentre outras. A agricultura modernizou-se extraordinariamente no século XX, especialmente na segunda metade, com o uso maciço de novas tecnologias que multiplicaram a produtividade brasileira e mundial. Esse fenômeno ficou conhecido como mundialização da agricultura, segundo Oliveira (2016), que integra novos procedimentos com o uso do solo, de intensificação da adoção de produtos químicos variados e sementes transgênicas, sensoriamento remoto e intensa mecanização.

Essas transformações, por outro lado, agudizaram a concentração de terras e de riqueza no campo. Estimulou o êxodo rural, acelerado e desorganizado, vulnerabilizando milhões de 
brasileiros nas periferias das cidades. O modelo agrícola preconizado fundamenta-se na produção em larga escala voltada aos mercados interno e externo, especialmente para a produção de commodities, com pouco uso de mão de obra humana, o que repeliu milhões de pessoas. Com isso, crescia a necessidade de assimilar esse contingente populacional nas cidades, com empregos industriais, quiçá na promissora indústria de máquinas agrícolas. Aí reside a contradição que apresentamos: como o Brasil, um país de vultosa produção agrícola, uma das três maiores do planeta, amplo mercado consumidor de tratores e colheitadeiras, organizou historicamente e estruturalmente a indústria de máquinas agrícolas? Quais interesses sobrepuseram-se na vida nacional?

Mediante a metodologia materialista, histórica e dialética, discutida por Besse e Caveing (1995), apresentam-se neste artigo releituras bibliográficas da história econômica do Brasil no período de 1920 a 2020, as concepções de desenvolvimento que permearam os embates políticos, os avanços e insucessos do segmento industrial de máquinas agrícolas, ilustrados por dados oficiais e corporativos. Nesse período, notam-se marcadamente, três etapas bastante distintas para o desenvolvimento do segmento industrial de máquinas agrícolas: 1) A revolução industrial brasileira e a gênese do segmento de máquinas agrícolas; 2) A consolidação da indústria nacional e a disputa com o mercado estrangeiro; 3) A desnacionalização.

Assim, com referencial teórico de autores que debatem a história econômica, a geografia econômica e a teoria econômica, ressaltam-se as distintas concepções acerca do desenvolvimentismo. Com isso, traz-se uma discussão sobre a historicidade da significação do segmento para a economia nacional, de empresas genuinamente brasileiras digladiando-se com a voracidade do capital externo, refletindo distintas posições de agentes públicos, contextualizados na história política e econômica do Brasil. Essa reflexão será embasada em revisão bibliográfica, dados oficiais (IBGE) e corporativos (ABIMAQ, ANFAVEA), que nortearão a apresentação da historicidade do segmento de máquinas agrícolas e considerações sobre sua realidade atual.

\section{Desenvolvimentismo em disputa e a indústria de máquinas agrícolas no Brasil}

Historicamente, o Brasil apresenta um cenário de intensas disputas ideológica, cultural, política e econômica. Com as transformações ocorridas na segunda metade do século XIX no mundo, a II Revolução Industrial e a busca pela expansão geopolítica de potências industriais europeias e, em seguida, os Estados Unidos, o país também vivencia suas mudanças internas. Ocorrem a abolição da escravidão e a proclamação da República, mas mantem-se sob outra 
roupagem o domínio estrangeiro na aliança da oligarquia cafeeira com capitalistas ingleses e estadunidenses. Encontra-se nesse contexto e o sucede o debate sobre o desenvolvimento do Brasil.

Concepções desenvolvimentistas

Para Bloch (2001), o objeto da história são os homens, sendo o tempo histórico a sua realidade concreta e viva, “o próprio plasma em que se engastam os fenômenos e como o lugar da sua inteligibilidade.” Segundo Sodré (1962) a História é uma ciência social e seu objeto é o conhecimento do processo de transformação da sociedade ao longo do tempo. Para o autor, a base da vida em sociedade é a produção, em que é preciso produzir e, para tanto, é preciso trabalhar. As relações de trabalho unem e constituem a sociedade, na relação com a natureza. Historicamente, transformou-se o grau de desenvolvimento dos instrumentos de produção e isso indica o poder da sociedade sobre a natureza e o seu grau de desenvolvimento. As épocas econômicas distinguem-se não pelo que os homens produzem, mas como produzem, isto é, que instrumentos de produção empregam.

As relações que se estabelecem na produção são relações sociais: constituem objeto da História. Elas definem a sociedade sob três aspectos: — forma de propriedade sobre os meios de produção, que é uma relação determinante; situação social consequente, com a divisão da sociedade em classes; - formas de distribuição da produção, estabelecendo os nexos entre a produção e o consumo. (SODRÉ, 1962, p. 3)

Segundo Santos (2003), a técnica não aparece isolada, mas em sistemas técnicos, os quais correspondem a conjuntos de técnicas hegemônicas num dado momento. Assim sendo, as diferentes técnicas e objetos distinguem os períodos históricos. Para além, o trabalho e as técnicas de cada época caracterizam seu tempo e seu espaço. Para Engels (1980), do trabalho produtivo baseado nos laços de parentesco, desenvolveram-se a propriedade privada e as trocas, as diferenças de riqueza e a possibilidade de empregar a força de trabalho, gerando com isso a luta de classes.

Segundo Hettwer (2019), in Diniz (2006), na análise etimológica, é possível perceber que, com a junção dos elementos que compõem a palavra desenvolvimento, forma-se algo que poderia ser expresso como: "sem movimento para reverter a ação" ou ainda "sem envolvimento". É autenticamente uma expressão repleta de significado dialético. Isso nos remete a uma reflexão de que é preciso algo para gerar o movimento e/ou envolvimento. 
Entretanto, o que seria esse algo? Para qual direção o movimento se conduz? Envolver para quê?

Pois, o termo vem sendo adotado tanto por pensadores e ideologia neoliberal que referendam a etapa monopolista do capital e suas consequências segregadoras para a humanidade, quanto por preocupados pensadores progressistas, ávidos pela emancipação dos povos. Assim, é preciso posicionar-se criticamente diante do uso indevido para o real progresso humano contido na concepção neoliberal, unicamente discursivo do conceito, que busca, tão somente, legitimar a perpetuação da dominação de uns poucos sobre a população fixando no imaginário popular esse domínio, naturalizando-o.

Para Fonseca (2015), não há uma simples e consensual conceituação do desenvolvimentismo, refletidos pela antiga controvérsia epistemológica entre idealismo e materialismo. Se a opção for por ideologia, a direção dá-se do pensamento para a matéria.

Já se a conceituação parte da política econômica, o caminho é inverso: o desenvolvimentismo é entendido primordialmente no campo material da história: trata-se de uma política econômica efetivamente praticada por governos em determinado tempo e lugar. Por certo, desde cedo, o desenvolvimentismo apareceu também como pensamento ou ideologia para sugerir ou justificar um projeto de mudança, como antes se mencionou. Todavia, esta última opção, embora contemple no conceito de desenvolvimentismo as ideologias $\mathrm{e}$ as teorias, supõe que estas necessariamente estão inseridas em determinada experiência histórica, e é esta que lhes dá razão de existência e sentido. (FONSECA, 2015, p. 39)

Fonseca (2015), opta pelo caminho epistemológico materialista pois este respalda-se também no fato de que o aparecimento de governos nacional-desenvolvimentistas em vários países latino-americanos no século XX "sugere que este não foi um fenômeno aleatório, randômico, ou "importado".

Devemos conceber o desenvolvimento como um processo que encontra a sua definição na finalidade a que se dirige. Não se trata do conceito vago e impreciso de finalidade em geral, mas de finalidade rigorosamente fixada e lucidamente compreendida, pois, sem a clareza e a exatidão dos fins visados, o processo não se poderia constituir, e não teria sentido, então, falar propriamente em processo. Daqui se descortina a possibilidade da ideologia do desenvolvimento nacional ser não um esquema conceitual, abstrato e improdutivo, mas concepção geral (geral, não abstrata) de que decorrem linhas inteligíveis de ação prática rigorosa. (VIEIRA PINTO, 1960, p. 22)

O desenvolvimento nacional, portanto, é um processo histórico de determinados espaço geográfico e sociedade, a nação. Para tanto, seria preciso construir uma ideologia de desenvolvimento nacional, segundo Furtado (2009), uma vez que a dependência ideológica precede às demais dependências financeira e tecnológica. O nacionalismo, por sua vez, é um fenômeno histórico intrínseco à existência da nação, é a consciência autêntica e crítica da 
realidade nacional. De outra parte, para Furtado, o subdesenvolvimento contemporâneo não constitui uma etapa necessária do processo de formação das economias capitalistas modernas. É, em si, um processo particular, resultante da penetração de empresas capitalistas modernas em estruturas arcaicas.

O fenômeno do subdesenvolvimento apresenta-se sob várias formas e em diferentes estádios. O caso mais simples é da coexistência de empresas estrangeiras, produtoras de uma mercadoria de exportação, com uma larga faixa de economia de subsistência, coexistência esta que pode perdurar, em equilíbrio estático, por longos períodos. (FURTADO, 2009, p. 171).

Acerca do desenvolvimento industrial brasileiro no século XX, Draibe (1996) destaca a necessária discussão do "Conceito de Revolução Burguesa” de Florestan Fernandes que permite a compreensão da especificidade do processo de transformação capitalista ocorrido no Brasil.

Para Florestan Fernandes, a Revolução Burguesa no Brasil compreende "um conjunto de transformações econômicas, tecnológicas, sociais, psicoculturais e políticas" que não se realizam de um golpe mas ao longo de um período de .30 anos, e só se completam quando o desenvolvimento capitalista no Brasil atinge sua base industrial. O que a Revolução Burguesa no Brasil tem de específico é que, diferentemente das revoluções burguesas clássicas, ela não constitui apenas um momento político, em que a burguesia toma de "assalto" o controle de poder e do Estado, mas sim, um processo de transformação continuada, em que, ao mesmo tempo, tanto se constrói a estrutura econômicoindustrial, como se formam e se diferenciam as classes sociais e as estruturas políticas do próprio Estado. (DRAIBE, 1996, p. 160)

No estágio desigual de desenvolvimento internacional, distintamente das narrativas, os Estados que se desenvolveram fizeram-no contrariando sua própria retórica para os demais países. "É um expediente muito comum e inteligente de quem chegou ao topo da magnitude chutar a escada pela qual subiu a fim de impedir os outros de fazerem o mesmo." (LIST, 1885, p. 295)

Assim, segundo Singer (1983), o mundo se dividiu, de forma cada vez mais nítida, em países desenvolvidos, exportadores de produtos industriais, e países não-desenvolvidos, exportadores de produtos primários. Nas nações que se desenvolveram, o Estado foi estratégico para tanto. Ele não se limitou a criar as condições econômicas e institucionais adequadas para o desenvolvimento, mas foi também o promotor deste. (BRESSER-PEREIRA, 2004, p.57).

A contradição conceitual de desenvolvimento perdurou por todo o século $\mathrm{XX}$, com distintas concepções. Na década de 1980, ascende uma nova ideologia, a partir da Grã-Bretanha e Estados Unidos, o neoliberalismo, que mais uma vez vai buscar impor dogmas liberais e sacrificar as defesas nacionais, preconizando o Estado mínimo, o livre-mercado irrestritamente, a desproteção nacional, que contaminou corações e mentes e intensificou o domínio das grandes corporações de alguns países na etapa monopolista do capitalismo financeiro, o que Souza 
(1995) desprezou ser uma teoria científica, mas denominou como a ideologia da oligarquia financeira que domina o mundo, na atual etapa do capitalismo.

A ocupação das transnacionais ocorreu num cenário de intenso avanço da técnica, especialmente de comunicações e transporte, numa nova etapa da globalização. Conforme Sevcenko (2009), as megacorporações adquiriram um grande poder de mobilidade, redução de mão-de-obra e capacidade de negociação - podendo deslocar suas plantas para qualquer lugar onde paguem os menores salários, os menores impostos e recebam os maiores incentivos, tornando a sociedade e o Estado seus reféns.

Para Roio (1998), agrava-se a desigualdade e o domínio de alguns países pois, enquanto a soberania dos Estados subalternos é refém da movimentação global do capital financeiro, os Estados imperialistas e suas instituições têm sua capacidade de decisão transferida para burocracias internacionais mais adequadas a gerir os interesses da oligarquia financeira do império global. Harvey (2004), ressalta a hegemonia dos Estados Unidos nos últimos cinquenta anos, especialmente após o colapso da URSS, como o novo centro irradiador desse império global, tendo o país "recorrido com frequência à dominação e a coerção, não hesitando em liquidar a oposição", seja internamente ou externamente, de maneira ainda mais intolerante.

Entraves históricos à industrialização brasileira

O Brasil tardou a industrializar-se, moldado pelas imposições colonialistas de Portugal e da Inglaterra. Segundo Prado Jr (2008), até sua consolidação no século XX, a indústria no Brasil teve alguns surtos descontínuos. Segundo o historiador e geógrafo, desde a abertura dos portos em 1808, que atraiu as mercadorias estrangeiras ao país com tarifas alfandegárias muito baixas, aniquilando a produção nacional, a indústria brasileira teve outras sérias dificuldades: deficiência das fontes de energia, ausência da siderurgia, desconhecimento da existência de carvão mineral, e, sobremaneira, a insignificância de um mercado interno, num país continental desconectado e com ilhas regionais produtivas voltadas ao exterior.

Contudo, em 1844, o aumento de tarifas alfandegárias a produtos estrangeiros, a queda do câmbio que encarecia ainda mais produtos importados, facilitou surtos industriais posteriores, por vezes interrompidos pela predominância dos interesses dos proprietários rurais que desejavam o câmbio favorável à exportação e a fidelização de seus mercados alvo - Europa e EUA. Outros fatores favoráveis eram a abundância de matéria prima, especialmente o algodão, para a indústria têxtil, e a mão de obra muito barata. 
O primeiro surto apreciável, segundo Prado Jr.(2008), ocorreu no período 1880-1889, com o número de estabelecimentos industriais ascendendo de pouco mais de 200 em 1881 para mais de 600 em 1889, sendo $60 \%$ na indústria têxtil, $15 \%$ na de alimentação, $10 \%$ na de produtos químicos e análogos, $4 \%$ na indústria de madeira, 3\% na de vestuário e objetos de toucador e 3\% na metalurgia. Em 1907, no primeiro censo das indústrias brasileiras, havia 3.258 estabelecimentos, majoritariamente têxteis e de alimentação, que empregavam 150.841 operários, sendo 33\% no Rio de Janeiro, $16 \%$ em São Paulo e 15\% no Rio Grande do Sul, salientando-se que nenhum outro estado alcançara $5 \%$.

A proclamada República iniciou em 1894 o período conhecido como República do Café com Leite, ou República Oligárquica (poder de poucos), baseado centralmente na manutenção do país como uma economia agroexportadora de café e importadora de produtos industrializados, especialmente da Inglaterra e dos EUA.

Nessa época, o eixo da economia brasileira passou a ser a produção e a exportação do café. Reproduzia-se com a República a economia agroexportadora que caracterizou o Brasil desde sua origem colonial. E, nessa economia, cabia aos bancos ingleses aportar os recursos financeiros para produção, transporte e comercialização do café e aos industriais ingleses fornecer produtos manufaturados para o Brasil. (SOUZA, 2007, p. 2)

Para Prado Jr. (2008), outro surto industrial importante foi proporcionado pela eclosão da I Guerra Mundial, especialmente na Europa, que diminuiu drasticamente a entrada de importados europeus de países em conflito, e ainda possibilitou a produção nacional, a substituição de importados e a exportação brasileira. No censo industrial de 1920 foram registradas 13.336 indústrias, principalmente de alimentação $(40,2 \%)$, e têxteis.

Passada a I Guerra Mundial, com a contínua submissão política brasileira ao capital estrangeiro para beneficiar a aliança cafeicultora, e com a intensificação produtiva proporcionada pela II Revolução Industrial2 em alguns países - EUA, Inglaterra, França, Holanda, Bélgica, Alemanha, Itália, ocasionada na segunda metade do século XIX a meados do século XX, ampliaram-se os interesses sobre o Brasil, desindustrializado, de considerável mercado interno, oferta abundante de matérias primas e mão de obra muito barata. No período que vai de 1924 a 1930, crescem as importações de manufaturas e, sobretudo, radicaliza-se um processo: a instalação no Brasil de indústrias subsidiárias de grandes empresas estrangeiras.

\footnotetext{
${ }^{2}$ A Segunda Revolução Industrial corresponde à continuidade e expansão territorial do processo de revolução na indústria com o aprimoramento de técnicas, o surgimento de máquinas e a introdução de novos meios de produção, com o ferro, o carvão e a energia a vapor, característicos da primeira fase da Revolução Industrial, dando lugar ao aço, à eletricidade e ao petróleo. Diversos inventos como o dínamo, o motor à combustão, a energia elétrica, dentre outros, vão dinamizar os sistemas produtivos a menor custo e menor tempo, em modos de organização conhecidos como taylorismo e fordismo.
} 
Essa questão impactará drasticamente a história brasileira nas décadas seguintes. Essa contradição ideológica, herdada da dinâmica colonialista, mantida pelas elites, mas que dialeticamente intrigava a vontade nacional emancipatória, cada vez mais vai pautar a vida política, econômica, social e cultural do país. Os conflitos intensificam-se à medida que cresce a carestia, com a crise de 1929, que fez sucumbir o modelo agroexportador monocultor do café, que se arruína.

Ao mesmo tempo, nas diversas batalhas populares travadas no início do século XX, o Brasil e seu povo cada vez mais se descobrem, às suas potencialidades e forja-se uma identidade nacional, inspirada pela greve geral de 1917, pelos movimentos revolucionários tenentistas, pela Semana de Arte Moderna de 1922, até culminar na Revolução de 1930, que promove rupturas paradigmáticas na concepção nacional e estabelece o projeto nacionaldesenvolvimentista, sob a liderança de Getúlio Vargas. Com ele, líderes tenentistas como Miguel Costa, Juarez Távora e João Alberto, além de lideranças jovens e idealistas - Oswaldo Aranha, Flores da Cunha, Lindolfo Collor e Francisco Campos, pretendiam reformular o sistema político vigente com a introdução de reformas sociais e a centralização do poder.

A Revolução de 1930, a industrialização nacional e a gênese da indústria de máquinas agrícolas

Segundo a Abimaq (2006), Getúlio Vargas comprou a ideia da força do trabalho industrial e tomou medidas para proteger e incentivar a indústria. Diniz (1978), aponta as dificuldades para a ascensão da burguesia industrial brasileira, num contexto de fortalecimento do Estado e os limites impostos pelas elites rurais. Assim, destaca o que denomina ser a cooptação da burguesia industrial pelo Estado, consistindo neste um engajado representante de seus interesses.

Vargas decretou o monopólio do câmbio e impôs moratória externa, abrindo caminho para as primeiras decisões estratégicas de uma política industrial no país. Instalou o Conselho Nacional do Petróleo (CNP); fundou a Companhia Siderúrgica Nacional (CSN), em 1941; criou a Companhia Vale do Rio Doce, em 1942; organizou uma empresa de economia mista para desenvolver a indústria de álcalis e eliminar os gastos em importação de barrilha, matéria-prima essencial à produção do vidro.

Em 1943, o governo põe fim à desregulamentação trabalhista criando a CLT (Consolidação das Leis do Trabalho), ensejando marcos de direitos aos trabalhadores brasileiros. Em 1953, Vargas criou o Banco Nacional de Desenvolvimento Econômico (BNDE) e, estrategicamente, nacionalizou o petróleo brasileiro, criando a Petrobras. A base do projeto 
nacional-desenvolvimentista consistia num tripé: a unidade do Estado, da empresa nacional e dos trabalhadores. A síntese do programa era assumir o controle nacional sobre as nossas riquezas; produzir no Brasil, através de empresas genuinamente nacionais - estatais e privadas - os bens cuja importação sangrava o país pela via das trocas desiguais; tomar como base do desenvolvimento a expansão do mercado interno; melhorar o poder de compra dos trabalhadores e proteger o trabalho da ganância do capital.

Leopoldi (2000), discute a significância do protecionismo como uma estratégia de industrialização, necessária e exitosa. Organizados em entidades corporativas, industriais brasileiros tiveram no Governo Vargas a ressonância para seus interesses. Politicamente, a autora questiona o fim do protecionismo no final do século $\mathrm{XX}$, propondo sua revisão, repercutindo as transformações políticas ocasionadas na Nova República.

Os resultados do nacional-desenvolvimentismo não tardaram a aparecer. Em 1938, a produção industrial já era o dobro da realizada em 1929. Segundo Furtado (2007), os países de estrutura econômica similar à do Brasil, que seguiram uma política muito mais ortodoxa, e ficaram, portanto, na dependência do impulso externo para recuperar-se, chegaram a 1937 com suas economias ainda em estado de depressão. Bastos (2006), entende que o nacionalismo econômico varguista defendia intervenção para o desenvolvimento, ou seja, não era apenas nacionalismo, mas nacional-desenvolvimentismo, imbuído de desenvolver economicamente o país através da diversificação de atividades voltadas para o mercado interno reduzindo a dependência externa, o que vai sendo aprimorado ao longo da trajetória política de Vargas.

As finalidades, os dilemas e a mutação das formas do nacionaldesenvolvimentismo podem ser avaliados como uma análise das políticas frente aos ramos então considerados básicos e prioritários para um desenvolvimento econômico moderno: a siderurgia pesada, a exploração do petróleo e, particularmente, o ramo de energia elétrica. Enquanto os dois primeiros não estavam constituídos antes de 1930, no terceiro já se concentravam as maiores filiais norte-americanas presentes no Brasil (Light e Amforp). (BASTOS, 2006, p. 242)

Vale ressaltar que os desafios nacionais eram imensos e diversos, em todos os setores da vida nacional. O Brasil era um país arquipélago, desarranjado produtivamente, mas, também, sem fundamentos básicos como educação e saúde. Somente em 1930 é criado o Ministério da Educação, com o nome de Ministério da Educação e Saúde Pública. Segundo o Inep (2001), em 1920, 65\% da população brasileira de 15 anos ou mais era analfabeta. Para fomentar a indústria nacional seria estratégico desenvolver pesquisa, ciência e tecnologia para gerar o conhecimento necessário para as transformações econômicas, técnicas, de infraestrutura, que o novo momento exigia. Em 1931, concebido pelo ministro da Educação e Saúde, Francisco 
Campos, foi aprovado o Estatuto das Universidades Brasileiras, popularmente conhecido como "Reforma Francisco Campos"; ali era determinado que:

[...] a universidade poderia ser oficial, ou seja, pública (federal, estadual ou municipal) ou livre, isto é, particular; deveria, também, incluir três dos seguintes cursos: Direito, Medicina, Engenharia, Educação, Ciências e Letras. Essas faculdades seriam ligadas, por meio de uma reitoria, por vínculos administrativos, mantendo, no entanto, a sua autonomia jurídica (OLIVEN, 2002, p. 3).

Foram criadas 22 universidades federais, constituindo-se o sistema de universidades públicas federais. Cada unidade da federação passou a contar, em suas respectivas capitais, com uma universidade pública federal, além de nove universidades religiosas, oito católicas e uma presbiteriana. Com essa medida, unida às demais, o Brasil lançava-se à pretensão de industrializar-se.

Bielschowsky (2000), destaca que conviviam cinco concepções desenvolvimentistas no Brasil no período: a neoliberal, três mais nacionalistas (privada, não nacionalista e nacionalista) e a socialista, todas embasadas em forte viés ideológico. A II Revolução Industrial criou as condições para o amplo desenvolvimento da mecanização agrícola, caracterizada pelas invenções do dínamo e do motor a combustão, dos usos do petróleo e do aço, da hidroeletricidade. Os países que mais rapidamente organizaram seus modos de produção e ainda possuíam em abundância os novos elementos básicos (aço e petróleo), que são os casos dos EUA e de nações europeias, aceleraram seus desenvolvimentos internos. Multiplicaram suas capacidades produtivas e vislumbraram outros países como excelentes oportunidades para ocupação com suas mercadorias. A Ford ocupou o mercado brasileiro e mundial com seu trator Fordson 1918, já montado nesse ano no país, ganhando escala nacional a partir de 1919 com a primeira fábrica em São Paulo. Em 1926, inicia a montagem de tratores, mas só fabrica o primeiro trator nacional em série em 1960, com a produção interrompida em 1967 e novamente retomada na década de 1970.

Porém, foi a iniciativa nacional que criou o primeiro trator produzido no país. Segundo Brandão (2018) e Scharinger (2020), na segunda metade da década de 1940, a Romi, com a marca Imor, de propriedade de Américo Emílio Romi3, de Santa Bárbara do Oeste (SP), fabricou por algum tempo o trator agrícola de origem alemã Lanz Bulldog, para o qual importava somente o motor. O Bulldog foi logo substituído por um modelo mais moderno,

\footnotetext{
${ }^{3}$ Américo Emílio Romi foi fundador das Indústrias Romi S.A., localizada no município de Santa Bárbara d'Oeste, SP. A empresa produziu o primeiro trator brasileiro, o Toro, e o primeiro carro de passeio fabricado no Brasil, o Romi-Isetta. Atualmente, figura como maior produtor de máquinas-ferramenta e máquinas para processamento de plásticos do Brasil, além da siderurgia.
} 
desenvolvido com o apoio de André Toselo, professor do Instituto Agronômico de Campinas equipamento de $32 \mathrm{cv}$ lançado em 1948 com o nome Imor Toro (das sílabas iniciais de Toselo e Romi). "Emílio teve a ideia de produzir tratores, que no Brasil todo não eram mais que 10 mil ou 11 mil. 'Ainda é tudo na enxada! Uma vergonha, e se orgulham de sermos um país agrícola!"” (BRANDÃO, 2018, p. 73)

Essa afirmação de Romi expõe a evolução contraditória de transformações radicais no campo brasileiro e mundial. Para Mazoyer e Roudart (2010), no século XX, houve uma segunda revolução agrícola, fundamentada em novos paradigmas de cultivo, de seleção de variedades mais exigentes em adubos e mais produtivas, a preparação de adubos minerais e tratamentos químicos específicos, além de intensa mecanização. Porém, no contexto brasileiro, perdurou a lógica de privilégios na oferta do capital através do crédito agrícola, agudizando a concentração fundiária e ampliando o fosso entre o camponês pobre e o latifundiário rico.

Certamente, esses novos meios de produção de custo muito elevado só foram adotados em sua totalidade pelos grandes estabelecimentos capitalistas ou estatais, e pelas camadas mais abastadas da agricultura patronal ou camponesa, enquanto, na falta de meios, a grande maioria do campesinato continuou com o cultivo manual, ou com o cultivo com tração leve, e não teve acesso, a não ser de modo muito limitado, às variedades melhoradas e aos adubos. A segunda revolução agrícola, após ter acarretado a queda do preço de muitos gêneros alimentares tropicais de base, conduziu também à redução dos preços de muitos produtos tropicais de exportação. (MAZOIER e ROUDART, 2010, p. 507)

Com a forçosa renúncia de Vargas em 1945, sucedeu-o o General Eurico Gaspar Dutra, que regrediu eixos do projeto nacional-desenvolvimentista, beneficiando o capital estrangeiro. Nomeou para Ministro da Agricultura o banqueiro Daniel Serapião de Carvalho, do conservador Partido Republicano. Conforme Braga (1998), Carvalho foi grande acionista da Companhia Nacional de Gás Esso, subsidiária da Standard Oil. Em 1949, o empresário paulista, Américo Emílio Romi foi discutir a questão produtiva nacional com o Ministro da Agricultura, Daniel Serapião de Carvalho. Romi ficou desolado com a negativa de apoio governamental, abandonou o projeto e não aguentou assistir ao trem ser lotado de carcaças, eixos, engrenagens de trator. "Quando começaram a carregar, deu as costas, agora um pouco curvadas, e se foi. A tristeza alimentava uma gastrite de anos. O assunto morreu, a ilusão foi enterrada." (BRANDÃO, 2018, p. 77)

A questão da dependência por motores era, e continua sendo, uma importante demanda da indústria de máquinas agrícolas. Em 1942, foi fundada por Vargas a Fábrica Nacional de Motores - FNM - empresa de economia mista para produção de motores para avião, mas com possibilidades de outros tipos de motores, inclusive para tratores, carros e caminhões. Segundo 
Kornis (2020), no ano de 1948, a FNM firmou um contrato com a empresa italiana IsottaFraschini, que resultou na fabricação do caminhão pesado a motor diesel FNM D-7.300, com um índice de 30\% de nacionalização. Em 1952, a FNM recebeu licença para montar caminhões da empresa italiana Alfa Romeo, atingindo um índice de nacionalização de $31 \%$.

No seu segundo mandato presidencial (1951-1954), Getúlio Vargas defendeu a manutenção da FNM como empresa estatal. Em 1953, a FNM obteve um empréstimo do BNDE para fazer face a investimentos complementares em ferramentas, máquinas e instalações adicionais em suas oficinas. Esse foi o primeiro auxílio financeiro recebido desde 1946 pela empresa, que até então sempre se mantivera com recursos próprios. Em 1955, ensaiou a fabricação de tratores, agora de origem Fiat, mas apenas cerca de mil unidades do modelo 25/R foram importadas pela FNM, às quais foram aplicados alguns componentes nacionais. (Paiva, 2004) e (Silva, 1968)

Com o tempo, sobressaiu-se na fabricação de caminhões e a linha de produção da FNM começou a mostrar resultados. A empresa, até então deficitária, chegou ao final de 1954 com lucro. Segundo Scharinger (2020), em 1955 a produção cresceu significativamente (2.426 unidades, contra 531 em 1954 e 373 em 1953). Embora, em 1956, os Fenemês representassem apenas $1,5 \%$ da frota brasileira de caminhões de porte médio e a gasolina, a marca brasileira produzia $20 \%$ do segmento de caminhões pesados a diesel, superando a Mercedes-Benz e Volvo. Em 1957, produziu automóveis, com a nacionalização do Alfa Romeo 1900, que originara o FNM JK.

Contudo, com a saída de Juscelino Kubitschek, a curta gestão de Jânio Quadros e a instabilidade política do governo de João Goulart, a FNM era alvo de constantes ataques, especialmente de ideólogos liberais atrelados ao capital estrangeiro. Segundo Scharinger (2020) e Souza (2007), mesmo lucrativa em 1965, a empresa padecia com tentativas de estrangulamento, já no período ditatorial, que restringia a concessão de recursos, provocava crises cíclicas por falta de capital de giro e inviabilizava investimentos que lhe permitissem completar as instalações industriais, ocupar a capacidade instalada, atingir níveis de nacionalização adequados e modernizar a linha de produtos.

Por fim, em janeiro de 1967, no regime militar, a FNM foi oficialmente "colocada à venda". Em maio de 1968, endossada pelo Ministro da Indústria e do Comércio, General Edmundo de Macedo Soares, que poucos anos antes fora vice-presidente da filial brasileira da Mercedes-Benz, houve a venda da estatal, para outra estatal, a italiana Alfa Romeo, que já negociava sua incorporação à Fiat. Anos mais tarde, em 1979, foram encerradas as atividades da FNM. 
A indústria nacional de máquinas agrícolas e a oligopolização estrangeira

No Governo JK foi criado o Grupo Executivo da Indústria Automobilística (GEIA), de ideário mais liberal, que regulou as diretrizes básicas relativas à indústria automobilística brasileira, cabendo ao órgão elaborar os planos para as diversas linhas de fabricação de veículos, examinando e aprovando privativamente os projetos referentes à indústria automobilística. Enquanto os investimentos estrangeiros deveriam ser encaminhados principalmente para a fabricação de veículos, caberia às empresas nacionais o subsetor de autopeças, devido à menor necessidade de capitais e à existência de vários produtores brasileiros. Constituiu-se, notadamente, um retrocesso no sentido nacional-desenvolvimentista trilhado por Vargas. JK, quanto aos bens de consumo duráveis, depositou inexequíveis expectativas nas grandes corporações internacionais, especialmente dos EUA, responsáveis por 43,5\% da entrada de IED (Investimento Estrangeiro Direto) no período de 1955 a 1963 no país por meio da Instrução no 113, conforme Caputo e Melo (2009).

Cerca de $70 \%$ desses capitais, nas duas modalidades, entraram sob a forma de máquinas e equipamentos, compostos basicamente de fábricas usadas, obsoletas nos EUA, mas "modernas" aqui, voltadas para a produção de bens de consumo de "luxo", destacando-se a indústria automobilística. (SOUZA, 2007, p. 31)

Mediante essa abertura escancarada ao ingresso do capital estrangeiro, plantas inteiras de transnacionais passaram a transferir-se para o Brasil, atraídos pela abundância de matériaprima e consolidação das indústrias de base, pela mão de obra barata e pelo crescente mercado interno. Ao mesmo tempo, as políticas governamentais desencorajavam os empreendimentos genuinamente nacionais, desassistidos diante da concorrência estrangeira, amplamente subsidiada e protegida nos seus países de origem.

Ainda assim, surgiram alguns projetos nacionais de destaque, como a Companhia Brasileira de Tratores (CBT), a Vemag S.A., a indústria de Máquinas Agrícolas Ideal, a Schneider, Logemann \& Cia. Ltda. (SLC), a Engesa (Engenheiros Especializados S.A.), a Müller S.A. Indústria e Comércio, a Malves, a Companhia Industrial Santa Matilde. Na Tabela 1 apresenta-se a caracterização destas importantes empresas, estratégicas ao desenvolvimento nacional, especialmente nas décadas de 1950, 1960, 1970 e 1980, principalmente.

Essas empresas chegaram a liderar o segmento de tratores nas décadas de 1960 e 1970, algumas produziram qualificadas colheitadeiras, com índices altos de nacionalização que chegaram a $95 \%, 97 \%$ e até $100 \%$, potencializando uma ampla e complexa cadeia produtiva. 
Contudo, todas essas empresas foram assimiladas por transnacionais ou faliram devido à penetração liberalizada do capital estrangeiro, seja pela ditadura militar ou por governos neoliberais de Fernando Collor de Melo e Fernando Henrique Cardoso.

\section{Tabela 1 - Relação de empresas nacionais de máquinas agrícolas}

\begin{tabular}{|c|c|c|c|c|c|}
\hline Empresa & Localização & $\begin{array}{l}\text { Anos de } \\
\text { duração }\end{array}$ & Especialidades & $\begin{array}{l}\text { Auge em } \\
\text { máquinas } \\
\text { agrícolas } \\
\end{array}$ & $\begin{array}{c}\text { Decadência em } \\
\text { máquinas agrícolas }\end{array}$ \\
\hline FNM & $\begin{array}{c}\text { Duque de } \\
\text { Caxias - RJ }\end{array}$ & $1942-1979$ & $\begin{array}{l}\text { Motores, caminhões, } \\
\text { tratores, automóveis. }\end{array}$ & $\begin{array}{c}\text { Décadas } 1950 \\
\text { e } 1960 \\
\end{array}$ & $\begin{array}{l}\text { Assimilada pela Alfa } \\
\text { Romeo (Fiat) } \\
\text { fechada } \\
\text { Volkswagen em } 1979 .\end{array}$ \\
\hline ROMI & $\begin{array}{c}\text { Santa } \\
\text { Bárbara do } \\
\text { Oeste - SP }\end{array}$ & $1930-\ldots$ & $\begin{array}{l}\text { Tratores, automóveis, } \\
\text { máquinas industriais. }\end{array}$ & 1948 & $\begin{array}{l}\text { Mudou de ramo de } \\
\text { atividade. }\end{array}$ \\
\hline CBT & $\begin{array}{c}\text { São Carlos - } \\
\text { SP } \\
\end{array}$ & $1960-1995$ & Tratores, jipes. & $\begin{array}{c}\text { Início década } \\
1970 \\
\end{array}$ & $\begin{array}{l}\text { Falida com } \\
\text { desprotecionismo } \\
\text { neoliberal em } 1995\end{array}$ \\
\hline SLC & $\begin{array}{l}\text { Horizontina } \\
\text { - RS } \\
\end{array}$ & $1945-1996$ & Colheitadeiras & Década 1970 & $\begin{array}{l}\text { Assimilada pela John } \\
\text { Deere (parte } 1979 \text { e } \\
\text { outra 1996) }\end{array}$ \\
\hline VEMAG & $\begin{array}{l}\text { São Paulo - } \\
\text { SP }\end{array}$ & $1952-1968$ & Tratores, automóveis & $\begin{array}{l}\text { Décadas } 1950 \\
\text { e } 1960\end{array}$ & $\begin{array}{l}\text { Assimilada pela } \\
\text { Volkswagen }\end{array}$ \\
\hline IDEAL & $\begin{array}{c}\text { Santa Rosa - } \\
\text { RS }\end{array}$ & 1953-1996 & $\begin{array}{l}\text { Colheitadeiras } \\
\text { implementos }\end{array}$ & $\begin{array}{c}\text { Décadas } 1960, \\
1970 \text { e } 1980\end{array}$ & $\begin{array}{l}\text { Assimilada pela } \\
\text { AGCO }\end{array}$ \\
\hline ENGESA & $\begin{array}{c}\text { São Paulo - } \\
\text { SP } \\
\end{array}$ & $1958-1993$ & $\begin{array}{l}\text { Tratores, blindados, } \\
\text { jipes, trólebus, trens, } \\
\text { caminhões. }\end{array}$ & $\begin{array}{l}\text { Décadas } 1970 \\
\text { e } 1980\end{array}$ & $\begin{array}{l}\text { Falida com } \\
\text { desprotecionismo } \\
\text { neoliberal em } 1993\end{array}$ \\
\hline MÜLLER & $\begin{array}{c}\text { Rio de } \\
\text { Janeiro - RJ }\end{array}$ & $1956-2002$ & $\begin{array}{l}\text { Tratores, } \\
\text { implementos } \\
\text { agrícolas, } \\
\text { compactadores. }\end{array}$ & $\begin{array}{l}\text { Décadas } 1970 \\
\text { e } 1980\end{array}$ & $\begin{array}{l}\text { Falida com } \\
\text { desprotecionismo } \\
\text { neoliberal em 2002 }\end{array}$ \\
\hline MALVES & $\begin{array}{c}\text { São Paulo - } \\
\text { SP } \\
\end{array}$ & $1956-1978$ & $\begin{array}{l}\text { Tratores, esteiras, } \\
\text { motoniveladoras. }\end{array}$ & Década 1970 & $\begin{array}{l}\text { Falida com perda de } \\
\text { contratos no leste } \\
\text { europeu. }\end{array}$ \\
\hline $\begin{array}{c}\text { SANTA } \\
\text { MATILDE }\end{array}$ & $\begin{array}{c}\text { Três Rios - } \\
\text { RJ }\end{array}$ & $1916-2005$ & $\begin{array}{l}\text { Colheitadeiras, } \\
\text { ônibus, tratores, } \\
\text { automóveis. }\end{array}$ & $\begin{array}{c}\text { Décadas } 1970 \\
\text { e } 1980 \\
\end{array}$ & $\begin{array}{l}\text { Falida com problemas } \\
\text { administrativos } \\
\text { desprotecionismo. }\end{array}$ \\
\hline
\end{tabular}

Fonte: Sharinger (2020), Andrade e Fernandes (1983), Brandão (2018), Fonseca (1990), Kornis (2020), Paiva (2004), Silva (1968). Org.: Hettwer, 2020.

$\mathrm{Na}$ atualidade, destacam-se duas empresas de máquinas agrícolas genuinamente brasileiras, as gaúchas Agrale e Stara. A Agrale foi fundada em 1962 com a denominação de Agrisa - Indústria Gaúcha de Implementos Agrícolas S.A., produzindo motocultivadores e seus motores diesel, assimilada em 1965 pelo Grupo Francisco Stedile, alterando sua denominação para Agrale S.A Tratores e Motores. Em 1968, lança o micro trator de quatro rodas Agrale 415, primeiro trator fabricado no RS, voltado à mecanização da agricultura familiar brasileira, ainda hoje em produção e líder em sua classe. Ao longo de sua história vem se notabilizando na produção de caminhões, motocicletas e ciclomotores, chassis projetados para micro-ônibus, 
viaturas 4x4 Agrale Marruá, o primeiro trator brasileiro a admitir o uso de biodiesel. (Agrale, 2020)

No município de Não-Me-Toque - RS, em 1953, surgiu a Stara, fundada por imigrantes holandeses, inicialmente para fazer manutenção e montagem de equipamentos agrícolas importados. Nos primeiros anos a empresa dedicou-se à produção de implementos agrícolas. Em 2009, passa a produzir pulverizadores autopropelidos. Em 2013, produz o trator ST Max 105, mantendo-se atualmente no mercado de máquinas agrícolas. (STARA, 2020) As duas empresas, Agrale e Stara, genuinamente nacionais, vêm desenvolvendo cada vez mais seus modernos implementos agrícolas, desafiando a dinâmica neoliberal, ousadamente focadas em colaborar na exploração nacional das potencialidades agrícolas brasileiras.

O domínio estrangeiro sobre a indústria de máquinas agrícolas

Estranhamente, a indústria nacional sucumbiu exatamente quando mais crescia a agricultura nacional e sua produtividade. Aproveitando-se da potencialidade brasileira, transnacionais que hegemonizam atualmente o mercado nacional, consolidaram-se no país a partir da década de 1970, com exceção da Massey Ferguson que se instalou em 1961, e da pioneira Ford, que já montava seus tratores em 1926 em São Paulo - deixou de produzi-los no país nas décadas seguintes, retomou a produção na década de 1970 mas foi assimilada pela Fiat na década de 1990. Na atualidade, segundo a Anfavea (2020), são associadas a ela e produtoras de tratores e colheitadeiras: a Agrale (única nacional, que produz apenas tratores e de menor potência), a italiana CNH (Case e New Holland), a estadunidense AGCO (Massey Ferguson e Valtra) e a também estadunidense John Deere.

A CNH Industrial (2020) foi criada em setembro de 2013, a partir da fusão da Fiat Industrial e CNH Global. A corporação italiana congrega mundialmente 12 marcas comerciais, 66 fábricas, 53 centros de pesquisa e desenvolvimento, mais de 63 mil empregados, presença em 180 países e receita líquida de US\$29,7 bilhões em 2018. Na América do Sul, são 10 fábricas, sendo sete no Brasil e três na Argentina que, juntas, geram mais de 8,5 mil empregos diretos. (Görgen, 2010)

A AGCO é uma corporação estadunidense que incorpora as marcas Challenger, Fendt, GSI, Massey Ferguson e Valtra. Segundo a AGCO (2020), a empresa detém 22\% das vendas globais na América do Norte em 1.830 concessionárias, 13\% das vendas globais na América do Sul em 250 concessionárias, 56\% das vendas globais em 1.620 concessionárias na Europa e Oriente Médio, e 9\% das vendas globais em 500 concessionárias na Ásia. 
Uma das mais longevas empresas do mundo, a John Deere, foi fundada em 1837, nos EUA. Segundo a Deere (2020), os equipamentos da marca John Deere estão presentes em 160 países ao redor do mundo, com a empresa empregando aproximadamente 58 mil pessoas em mais de 40 fábricas espalhadas por países como Estados Unidos, Canadá, Reino Unido, China, França, Alemanha, Argentina, Espanha, Itália, Índia, Polônia e México, sendo quatro no Brasil.

Relatórios da Anfavea demonstram que a evolução produtiva do segmento de tratores foi inconstante no período de 1960 a 2019, como mostra o Gráfico 1. Para a aquisição de máquinas agrícolas, além da produção disponível, há outras condicionantes como a situação econômica do país e do mundo, a demanda agrícola e concorrência internacional, bem como as necessárias ofertas de crédito agrícola como política pública.

Nota-se que o número de tratores produzidos em 1976 (64.175 unidades), quando havia forte presença nacional, é quase o dobro de 2019 (35.572 unidades). Nota-se ainda a queda abrupta na década de 1980, com um surto industrial com no Governo Sarney (1985/1989), nova derrocada e novo ápice em 1994, ano que coincide com a estabilidade da moeda brasileira, mas traz nova contenção no período do governo de Fernando Henrique Cardoso (1995/2002). No início do século XXI, com a retomada do crescimento econômico no governo Lula (2003/2010), houve novo surto industrial, declínio em 2006, até a escalada recorde em 2013, no governo Dilma Rousseff (2011/2016). Esses anos coincidem com a política agrícola e maior oferta de crédito para a aquisição de maquinário. Contudo, o domínio perpetuou-se estrangeiro. Desde então, a produção industrial brasileira vem retrocedendo, ainda que a safra agrícola e a geração de riqueza estejam cada vez maiores nos últimos anos.

\section{Gráfico 1 - Produção nacional de tratores com rodas no período 1960-2019}

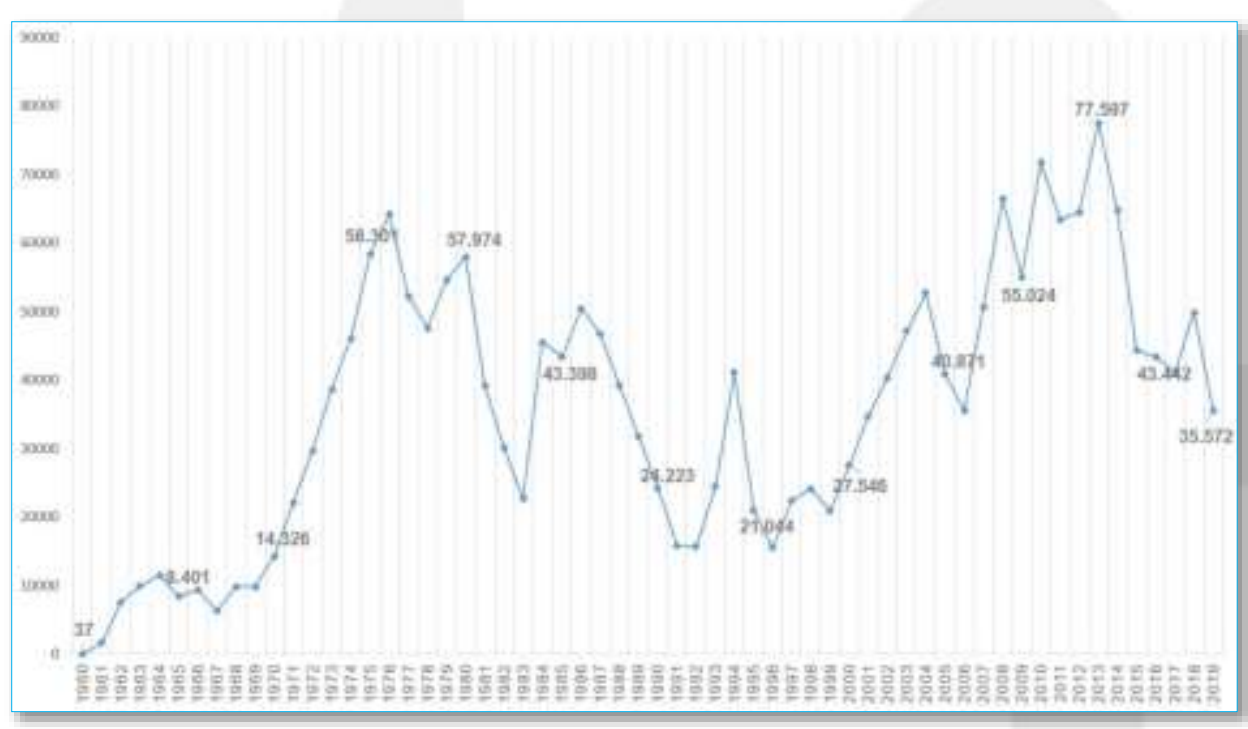

Fonte: Anfavea, 2020. Org.: Hettwer, 2020. 
A produção de colheitadeiras no período, ilustrada no Gráfico 2, apesar da grandiosidade atual da produção agrícola, é basicamente o mesmo em número de unidades no período: 6.481 (1976) e 6.310 (2019), ressaltando-se que em 1971 a população era de 93 milhões de habitantes diante da estimativa de 210 milhões de brasileiros em 2019. Com isso, questiona-se o atendimento ao conjunto de estabelecimentos rurais do país, mesmo considerando-se a evolução da produtividade/máquina e a concentração de terras. Os dois picos de produção de colheitadeiras ocorrem nos anos de 2004 e 2013, estimulados pela disponibilidade de crédito agrícola, ressaltando-se que uma unidade é bastante cara, com modelos que podem ser comercializados por mais de $\mathrm{R} \$ 1$ milhão.

\section{Gráfico 2 - Produção nacional de colheitadeiras de grãos no período 1976-2019}

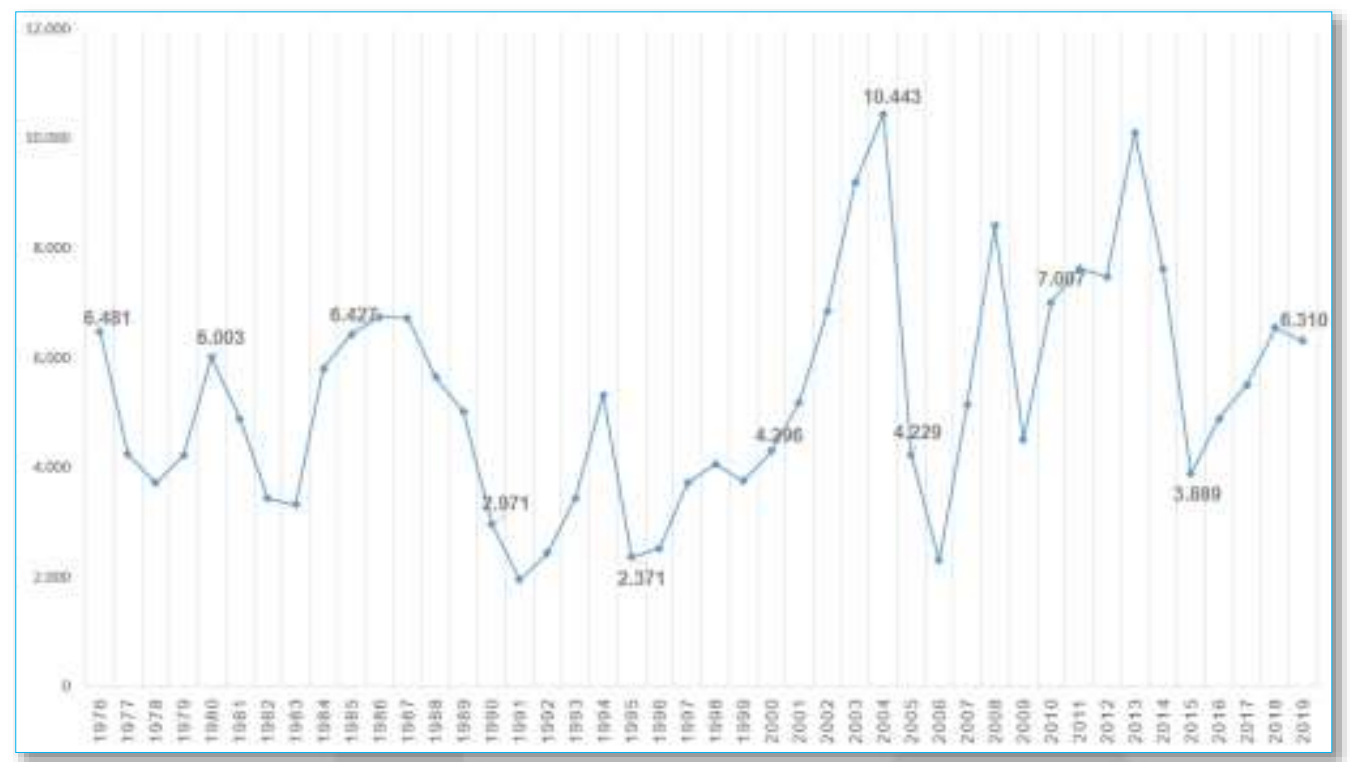

Fonte: Anfavea, 2020. Org.: Hettwer, 2020.

O Gráfico 3 apresenta a configuração atual do segmento de tratores agrícolas no Brasil, trazendo os números de produção das indústrias filiadas à Anfavea em 2019. 


\section{Gráfico 3 - Produção de tratores por empresa filiada a Anfavea em 2019 em unidades}

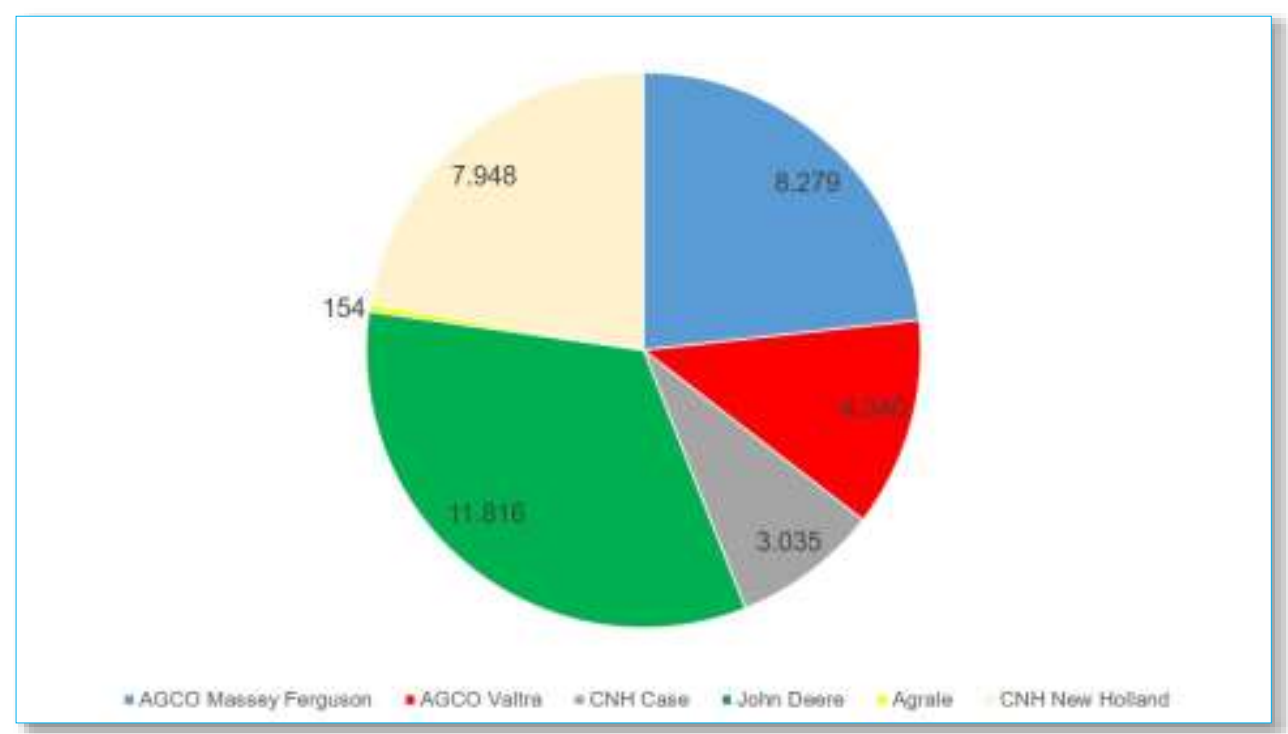

Fonte: Anfavea, 2020. Org.: Hettwer

Nota-se que a oligopolização estrangeira corresponde a 99,57\% das unidades produzidas, além da liderança da John Deere, seguida da AGCO Massey Ferguson, CNH New Holland, AGCO Valtra, CNH Case e da brasileira Agrale, com apenas 154 unidades produzidas no ano, consistindo em apenas $0,43 \%$ do universo de tratores produzidos.

Já o Gráfico 4 apresenta um cenário ainda pior para a indústria nacional, demonstrando que $100 \%$ da produção atual de colheitadeiras é estrangeira, com a liderança da John Deere, seguida pela CNH New Holland e CNH Case, AGCO Massey Ferguson e AGCO Valtra. Esse quadro contrasta com o período inicial da mecanização agrícola brasileira que apresentava empresas nacionais, mas que foram assimiladas pelo capital estrangeiro ou falidas pela desproteção nacional. Com o advento da ideologia neoliberal, a mundialização agrícola consolidou o domínio desse segmento industrial para as transnacionais, ao passo que coube ao país, guiado pela concepção subordinada, tão somente, apresentar-se como cliente dos produtos de alto valor agregado, oligopolizados, para, com eles, produzir commodities de baixo valor agregado, isenta de tributação, concentradora fundiária e muitas vezes danosa ao meio ambiente. 


\section{Gráfico 4 - Produção de colheitadeiras por empresa filiada a Anfavea em 2019 em unidades}

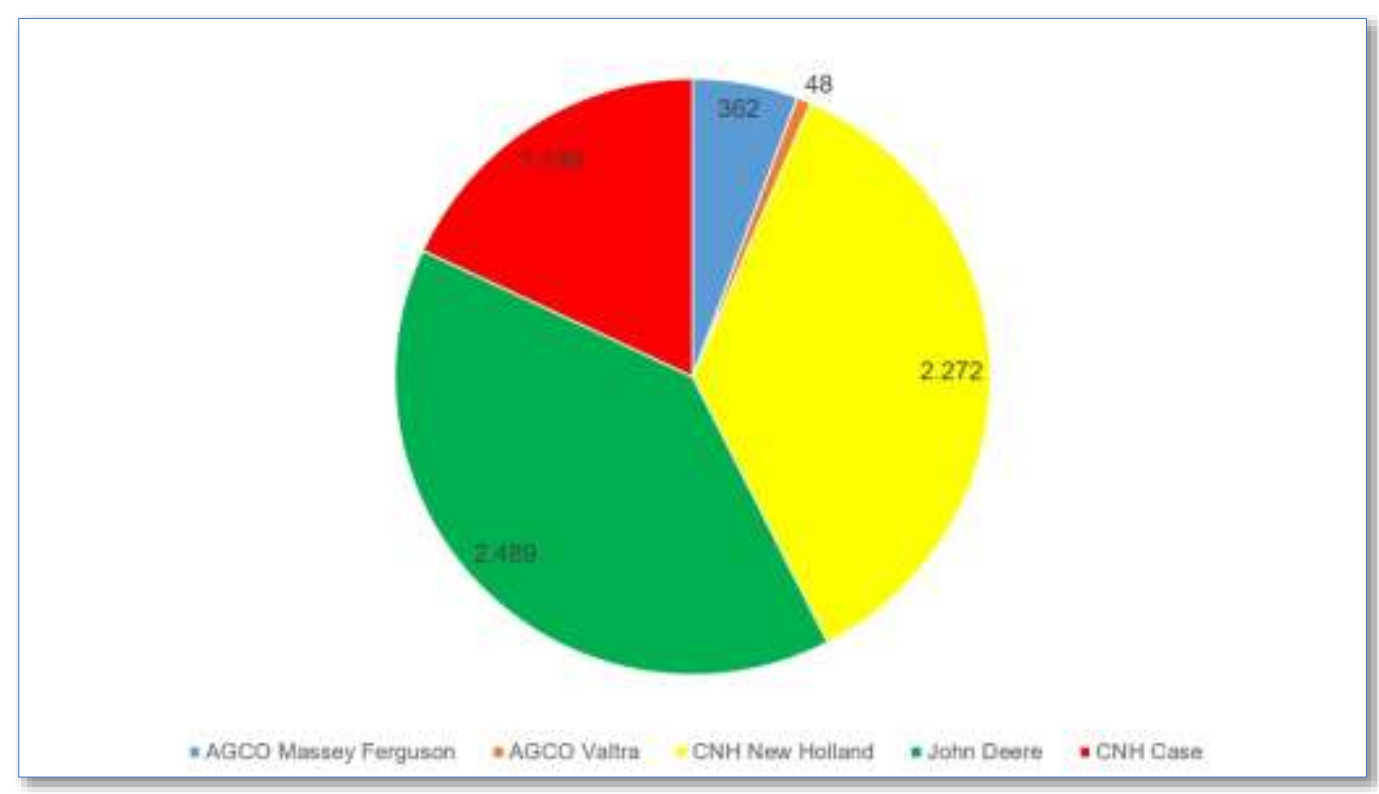

Fonte: Anfavea, 2020. Org.: Hettwer

Essa situação contradiz com a experiência histórica, asfixia a pesquisa e inteligência nacionais e contraria o dinamismo e potencialidade brasileira. O Brasil apresenta a maior biodiversidade do planeta, diversidade climática, solos férteis, relevo favorável à agropecuária, ausência de graves intempéries naturais, vasto território agricultável, abundância hídrica e mineral, múltipla disponibilidade de matrizes energéticas. Detém ainda uma indústria de base invejável montada no auge no projeto nacional-desenvolvimentista e significativo mercado interno consumidor e alta demanda por máquinas agrícolas. Alia-se a isso a capacidade científica e tecnológica dos centros de pesquisa nacionais - Embrapa, autarquias públicas estaduais, universidades - ainda que sofrendo graves e criminosos cortes orçamentários que só beneficiam a dependência tecnológica externa. Nesse contexto, parece inconcebível tamanha oligopolização estrangeira do maquinário agrícola brasileiro.

\section{Considerações finais}

Historicamente, há uma notável contradição brasileira: manter o país subdesenvolvido, colonial, produtor majoritário de commodities, de baixo valor agregado, tal como ilustraram Carlos Lyra e Chico de Assis do Centro Popular de Cultura da União Nacional dos Estudantes (CPC da UNE), em 1961, na "Canção do Subdesenvolvido", demonstrando a histórica e recorrente submissão brasileira à dominação cultural e econômica externa, ainda que 
ironicamente disfarçada como progresso, liberdade e igualdade. A alegoria inspira a dialética de domínio do capital estrangeiro nos segmentos em que este tiver o interesse, ou agigantar-se enquanto nação, desenvolver-se industrialmente, soberanamente, potencializando a cadeia produtiva primária com a crescente complexidade e agregação de valores dos demais arranjos produtivos possíveis. Essa é a fórmula das nações desenvolvidas e das que estão soberanamente desenvolvendo-se. Ao invés de escancarar as fronteiras e o mercado interno ao capital estrangeiro, os dados e discussões apresentados demonstram que é mister haver controle social sobre este e compromisso com o desenvolvimento nacional, especialmente nas áreas que o Brasil apresentar grande potencial e excelência, notadamente claros no segmento de máquinas agrícolas.

Segundo previsões do IBGE (2020) prevê safra de 253,2 milhões de toneladas para 2021, com alta de $0,5 \%$ frente a 2020. Ou seja, há um potencial crescente, mas explorado por um oligopólio estrangeiro, na produção de máquinas agrícolas. Considerando-se que o setor industrial é estratégico na geração de novas tecnologias, no encadeamento intersetorial, no potencial de crescimento da produtividade via economias de escala e penetração do progresso técnico, fica difícil a compreensão à desindustrialização brasileira e à desproteção da indústria nacional. O fortalecimento de genuína indústria nacional de máquinas agrícolas ainda geraria maior desenvolvimento regional e de maiúscula contribuição ao balanço de pagamentos.

Além dos históricos exemplos concretos da capacidade nacional, seja com a FNM, SLC, CBT, Engesa, comparativamente, assinala-se o caso da Índia, um país de dimensões agricultáveis bem menores que o Brasil, mas de numerosa população, possui uma indústria nacional de tratores que produz anualmente cerca de 250.000 unidades/ano, a Mahindra. Conclui-se que o caso do Brasil se resume a uma questão, lembrada por Celso Furtado como primordial: a necessária consolidação da ideologia nacional, apagados no período ditatorial e no neoliberalismo.

A completa independência do Brasil exige que sejam travados os mesmos embates experienciados por Delmiro Gouveia, Amélio Romi, Getúlio Vargas, e outros tantos brasileiros, que pensaram e lutaram pelo país por outro viés, realizando-se economicamente e tecnologicamente para o desenvolvimento do país. Afinal, não há sentido histórico que um país com a inteligência de Santos Dumont e a inventividade da FNM, Engesa, Embraer, Petrobras, permaneça produzindo grãos e extraindo ferro para exportá-los, consumindo produtos de alto valor agregado, estrangeiros. 


\section{Referências bibliográficas}

ABIMAQ. A história das máquinas. São Paulo: Editora Magma, 2006.

AGCO. Presença global. Disponível em https://www.agco.com.br/about/global-reach.html

AGRALE. História da Agrale. Disponível em https://www.agrale.com.br/pt/sobre-aagrale/institucional

ANDRADE, Roberto Pereira de; FERNANDES, José de Souza. Veículos Militares Brasileiros. São Paulo: Aquarius, 1983.

ANFAVEA. Anuário da indústria automobilística brasileira. São Paulo: PifferPrint, 2020.

ANFAVEA. 50 milhões de veículos produzidos. São Paulo: Autodata Editora, 2007.

BASTOS, Pedro Paulo Zahluth. A construção do Nacional-Desenvolvimentismo de Getúlio Vargas e a dinâmica interação entre Estado e mercado nos setores de base. Revista EconomiA, Selecta, Brasília (DF), v.7, n.4, p.239-275, dezembro 2006.

BESSE, Guy e CAVEING, Maurice. Politzer - Princípios fundamentais de Filosofia. São Paulo: Hemus, 1995.

BIELSCHOWSKY, Ricardo. O pensamento econômico brasileiro. $\mathbf{O}$ ciclo ideológico do desenvolvimentismo. Rio de Janeiro: Contraponto, 2000.

BLOCH, Marc. Apologia da história. Rio de Janeiro: Ed. Jorge Zahar, 2001.

BRAGA, Sérgio Soares. Quem foi quem na Assembleia Constituinte de 1946. Brasília: Câmara dos Deputados, Centro de Documentação e Informação, 1998.

BRANDÃO, Inácio de Loyola. Oficina de sonhos - Américo Emílio Romi, aventuras de um pioneiro. São Paulo: DBA, 2018.

BRESSER-PEREIRA, Luis Carlos. O conceito de desenvolvimento do ISEB rediscutido. Rio de Janeiro: UERJ - Dados - Revista de Ciências Sociais [en linea] 2004, 47. Disponível em $19 / 11 / 2017$

CAPUTO, Cláudia Caputo e MELO, Hildete Pereira de. A industrialização brasileira nos anos de 1950: uma análise da instrução 113 da SUMOC. São Paulo: Estudos. Econômicos, vol.39 no.3, 2009.

CNH INDUSTRIAL. História. $\quad$ Disponível em http://www.media.latam.cnhind.com/pagina/340/historia.aspx em 25/05/2020.

DEERE. Sobre nós e nossa história. Disponível em https://www.deere.com.br/pt/index.html em 25/05/2020.

DINIZ, Francisco. Crescimento e desenvolvimento econômico: modelos e agentes do processo. Lisboa, PT: Editora Sílabo, 2006.

DINIZ, Eli. Empresário, Estado e capitalismo no Brasil: 1930/1945. Rio de Janeiro: Paz e Terra, 1978.

DRAIBE, Sônia. Rumos e metamorfoses. Estado e industrialização no Brasil: 1930-1960. Rio de Janeiro: Paz e Terra, 1996.

ENGELS, Friedrich. A origem da família, da propriedade privada e do Estado. Rio de Janeiro: Civilização Brasileira, 1980.

FONSECA, Maria da Graça Derengowski. Concorrência e progresso técnico na indústria de máquinas para a agricultura: um estudo sobre trajetórias tecnológicas. Campinas: Universidade Estadual de Campinas. Disponível em: <http://www.repositorio.unicamp.br/handle/REPOSIP/285888>. Acesso em: 25/05/2020.

FONSECA, Pedro Cezar Dutra. Desenvolvimentismo: a construção do conceito. Texto para Discussão, $2015 . \quad$ Disponível

https://www.ipea.gov.br/portal/images/stories/PDFs/TDs/td_2103.pdf

FORD. História. São Paulo: Ford, 2020. Disponível em https://www.ford.com.br/sobre-aford/historia/ em 25/05/2020.

FURTADO, Celso. Desenvolvimento e subdesenvolvimento. Rio de Janeiro: Contraponto, 2009. 
GÖRGEN, Jorge. New Holland: há 60 anos construindo histórias. S/1: Ideia Comunicação Empresarial, 2010.

HARVEY, David. O novo imperialismo. São Paulo: Edições Loyola, 2004.

HETTWER, Henrique Rudolfo. Caminhos e descaminhos de desenvolvimento social e econômico - análise do espaço geográfico de Cachoeira do Sul-RS. Santa Maria: Manancial Repositório Digital da UFSM, 2019. Disponível em https://repositorio.ufsm.br/handle/1/18676 IBGE. IBGE prevê safra de 253,2 milhões de toneladas para 2021 , com alta de $0,5 \%$ frente a 2020. Rio de Janeiro: Estatísticas econômicas, 2020. Disponível em https://agenciadenoticias.ibge.gov.br/agencia-sala-de-imprensa/2013-agencia-denoticias/releases/29406-ibge-preve-safra-de-253-2-milhoes-de-toneladas-para-2021-com-altade-0-5-frente-a-2020 acessado em 10/11/2020.

INEP. Mapa do analfabetismo no Brasil. Brasília: Portal Inep, 2001. Disponível em http://portal.inep.gov.br/documents/186968/485745/Mapa+do+analfabetismo+no+Brasil/a53a c9ee-c0c0-4727-b216-035c65c45e1b?version $=1.3$

KORNIS, Mônica. Verbete da Fábrica Nacional de Motores. In: Dicionário Histórico Biográfico Brasileiro, CPDOC/FGV. Rio de Janeiro: CPDOC, 2010.

LEOPOLDI, Maria Antonieta P. Política e interesses na industrialização brasileira. As associações industriais, a política econômica e o Estado. Rio de Janeiro: Paz e Terra, 2000.

LIST, Friedrich. The National System of Political Economy. London: Longmans, Green, and Company, 1885.

MAZOYER, Marcel e ROUDART, Laurence. História das agriculturas no mundo - Do neolítico à crise contemporânea. São Paulo: Editora UNESP; Brasília, DF: NEAD, 2010.

OLIVEIRA, Ariovaldo Umbelino. A mundialização da agricultura brasileira. São Paulo: Iãnde Editorial, 2016.

OLIVEN, Arabela Campos. Histórico da educação superior no Brasil. In: SOARES, M. S. A. (Org.). A educação superior no Brasil. Porto Alegre: Unesco, 2002. p. 31-42.

PAIVA, Eduardo Nazareth. A FNM e a Indústria Automotiva no Brasil: Uma Análise Antitética sob o Ponto de Vista da Teoria Ator-Rede. Rio de Janeiro: Universidade Federal do Rio de Janeiro, COPPE/UFRJ, 2004.

PRADO JR, Caio. História Econômica do Brasil. São Paulo: Brasiliense, 2008.

ROIO, Marcos del. Globalização e Estado nacional. In A causa nacional: o futuro da nação brasileira. Org. Ipso. São Paulo: Editora Senac, 1998.

SANTOS, Milton. A Natureza do espaço: técnica, razão e emoção. São Paulo: Edusp, 2003. SEVCENKO, Nicolau. A corrida para o século XXI. São Paulo: Editora Schwarcz, 2009.

SCHARINGER, João F. A Produção Automotiva Brasileira: Um Catálogo Geral. Disponível em http://www.lexicarbrasil.com.br/ em 25/05/2020.

SILVA, Edmundo de Macedo Soares e. A Alienação da Fábrica Nacional de Motores: Razões e Soluções Encontradas. Brasília: Ministério da Indústria e do Comércio, 1968.

SINGER, Paul. Aprender economia. São Paulo: Brasiliense, 1983.

SODRÉ, Nelson Werneck. Formação histórica do Brasil. São Paulo: Editora Brasiliense, 1962.

SOUZA, Nilson Araújo de. O colapso do neoliberalismo. São Paulo: Global Editora, 1995.

SOUZA, Nilson Araújo de. Economia brasileira contemporânea de Getúlio a Lula. São Paulo: Editora Atlas, 2007.

VALTRA. Conheça nossa história. Disponível em https://valtra60anos.com.br/

VIEIRA PINTO, Álvaro. Ideologia e Desenvolvimento Nacional. Ministério da Educação e Cultura (MEC) / Instituto Superior de Estudos Brasileiros (ISEB), 1956. 